\title{
Tilting at windmills: BLDSC and the UK higher education community
}

\section{The Authors}

Derek Law, University of Strathclyde, Glasgow, UK

\begin{abstract}
Purpose - To provide an overview of, the relationship between the British Library and higher education libraries in the 1990s, with particular relation to document supply. It also goes on to explore current developments in scholarly communication.

Design/methodology/approach - The author played a role in several of the events described and uses the available literature to enlarge on a personal view of that decade.
\end{abstract}

Findings - The paper shows that the relationship was a strained one caused in part by a mismatch of resources, but is in any case dwarfed by the larger external forces and changing opportunities and technologies for scholarly communication.

Originality/value - Provides a record of the period. 


\section{Preamble}

For many of my generation, Maurice Line has been a dominating hero figure. His impact on document delivery services, never mind the rest of the profession is impossible to overestimate and certainly impossible to do justice to in a single article. Maurice can only be described in adjectives: iconic; iconoclastic; irreverent; impatient; towering; quick-witted; a gangling man of jagged edges, whether dancing or walking, whether expressing views or chairing meetings. And he presided over BLDSC at a time of rapid change, turning a local lending service into a global giant. The often difficult relationship between the British Library (BL) and higher education (HE) in the 1990s have tended to conceal quite how much was achieved under his leadership. To take the most obvious example, Line was closely associated with IFLA's core programmes - notably the Universal Availability of Publications (UAP), whose office was based for many years at Boston Spa. One of the most astonishing, if least remarked, feats of international librarianship, is the completion of the UAP and its partner UBC (Universal Bibliographic Control) programmes which IFLA declared closed in 2003. Line must take much of the credit for the fact that it is broadly possible to identify any book or journal article published in the last 50 years (at least), to fill in a form, often electronically, and within a matter of days the work arrives.

Even more astonishing is the way in which libraries, on receiving a form, will send a book to the ends of the earth in the expectation that in due course it will return to the shelves. And yet there is no self evident reason why the British Library should work with common standards, a common currency and common practices with the Sydney Public Library, or the National Library of Medicine with the Max Planck Institutes or Edinburgh University Library with Shanghai City Library. We take international document delivery so much for granted that we have never sat back and analysed just how remarkable, how complicated and how difficult a triumph of professional cooperation it is (Parent, 2004). And if many others deserve credit, and Maurice would be the first to wish that to be so, then we should not forget in a currently fashionable if much mis-used phrase, that it happened on his watch.

\section{BLDSC and changing collection development strategies}

But the story to be told here really begins almost 30 years ago in 1976 with the publication of the now largely forgotten Atkinson Report (University Grants Committee, 1976). In a foreword to the Report, Lord Dainton, Chairman of the UGC, said: 
By the end of 1974 the UGC had come to the conclusion that they were clearly not going to have enough resources, either in the short term or the long term, to build new libraries at all universities on the scale needed to match an indefinitely growing number of books. Even if this had been possible, it was doubtful whether it would have been the most sensible course to follow.

So with Atkinson came the notion of the "self renewing library of limited growth" i.e. a library in which space required for new acquisitions would be provided largely by space created by withdrawals. The report coloured thinking for almost 20 years. The emerging serials crisis and escalating costs at a time of almost static budgets had forced librarians to start looking at novel solutions. The phrase of the moment was access versus holdings, alternatively described as a move from just-in-case collections to just-in-time services. By 1987 the situation seemed critical with a report (Pocklington and Finch, 1987) suggesting that the deep cuts in HE library provision were having an impact on research output and that the BL too was suffering cuts just when HE libraries needed more not less back-up. Increased co-operation and substantial investment in IT systems was at best mitigating the position in HE.

At that time, BLDSC occupied a singular and totally dominant position in remote supply. Its collections seemed comprehensive and its services were efficient and effective and relatively cheap. But throughout the 1980s the rapid development of library IT systems and the creation of UK consortia based on common IT platforms (BLCMP, LASER, SCOLCAP, SWALCAP) allowed models commonly practised in the USA to be explored. For example at one extreme it was possible to begin to think of the solution to the ever escalating cost of journals as being to rely entirely on BLDSC. Work at the University of East Anglia (Baker, 1992) concentrated on developing a matrix which would determine when it was more cost effective to move from subscription to transaction based access, relying on high quality document delivery services. But it also became possible to think of other models for document supply, based on regional or subject models. As always and even after leaving the BL, Line was a trenchant player in the debate, typically arguing against the prevailing fashion and concluding that access services could best act as a substitute for older not current material, where serendipitous browsing was a key feature of information gathering behaviour (Line, 1995).

This period of BLDSC dominance may now be seen to have ended just after Line's retirement (a technically accurate but totally inappropriate term) with the decision in 1990 by the Computer Board - the forerunner of JISC - to fund the ISI databases, hosted at the University of Bath as the Bath Information and Data Service (BIDS). This first example of a national site licence both showed that there was a role for JISC to act on behalf of the sector and was perhaps the first significant general service to the desktop, whetting academic appetites for easy unmediated access to the primary and not just the secondary literature. Its immediate success was followed by JISC's stated aim to move into dataset provision with large ambitions and a large budget (Law, 1995). In effect the HE community demonstrated its intention to use technology to address the issues.

\section{The Follett Report}


A seminal event for UK university libraries was the Follett report of 1993 (Higher Education Funding Council for England, 1993) which produced a sudden flush of cash and activity in higher education. In many ways the Follett Report was a middle point not a beginning, since much of the work on the IT related elements which would feature in the report had been done even before Sir Brian was appointed to chair the Committee (Brindley, 1996). Millions were released for everything from library buildings to IT projects. The eLib programme started in 1995 with funding of $£ 15,000,000$ over three years (Rusbridge, 2001). The aim of eLib was to "transform the use and storage of knowledge in higher education institutions". The first phase of the programme was quickly set up, bids sought and projects funded. Some 354 bids were received, again showing the pent-up energy in the sector. The successful bids were organised into a number of discrete strands, as:

- document delivery - four projects;

- electronic journals - ten projects;

- digitisation - four projects;

- on-demand publishing - seven projects;

- training and awareness - four projects;

- $\quad$ supporting studies - five projects.

The intention was to break the mould. It was accepted from the start that a programme of projects which delivered on time and on budget but failed to influence both culture and thinking was less desirable than a programme whose projects failed to deliver on time or on budget but which did change culture and thinking. It was a time of almost messianic zeal in which the BL was seen as increasingly irrelevant to the needs of HE.

\section{The British Library and higher education in the 1990s}

If the early 1990s were the best of times for higher education, they were perhaps the worst of times for the British Library. The Follett Report had led to an infusion of cash into the HE library sector which was bursting with ideas for innovation and the use of new technology, for the provision of national services and great enthusiasm for a period of rapid change. The very name of Follett Implementation Group for IT (FIGIT) embodied the restless energy which the eLIB programme would channel into literally dozens of projects, while at the same time the Information Services SubCommittee of JISC had an annual budget of millions to set up data services, the Arts \& Humanities Data Service, image services, subject based portal services and much more. It (not always fairly) saw the British Library as sclerotic, with a poor track record on IT innovation, stultified by financial problems and with an introverted if understandable concern with little beyond the new St Pancras building. In terms of document supply it was seen as a near monopoly supplier with no clear intention to move towards electronic document delivery, a goal prized by the HE community (Law, 1999; E-SYS, 2000). This breakdown of understanding was typified by two substantial post-Follett investments. There had been a great deal of rumour over the possibility that the BL would charge for the use of its online catalogue. This was anathema to the rather better heeled HE sector and was a direct cause - although by no means the only cause - of the setting up of COPAC as a free public service on the internet. Equally impatient with what was seen as the failure to move on electronic document delivery, FIGIT set out with an interlending research strand whose implicit aim was to change the BL from a library of first resort to a library of last resort. In 
fairness, the BL had conducted a great deal of experimentation. If it was unrealistic to expect a service with millions of transactions to be automated quickly or easily, there was nevertheless a real frustration at the gap between good research and its apparent non-implementation (Tuck, 1995).

\section{Electronic document delivery and the Follett Report}

This area was supported under phase 1 of the eLib programme. A general action to look at the Research Libraries Group ARIEL software in conjunction with Australian libraries was linked to four projects.

The biggest project under this strand was London and Manchester Document Access (LAMDA). It originated from several premises. First there was the view that the sheer excellence of the BLDSC service had both prevented any real research into alternative models and mitigated against technical development; it was frustrating to see the continued dominance of postal delivery when JANET had put instant communication into every university. Second, worry over pressures on BL charging policies as a result of budgetary problems and copyright fees meant that the search for alternative models was seen as financially important. As a result LAMDA loans were priced quite aggressively. Third, the supplying libraries saw document supply both as providing an alternative source of income for their overstretched budgets and through increased use as a justification for the continuing investment in these collections. Fourth, technology was readily to hand in the shape of the Research Libraries Group ARIEL software, which allowed cheap scanning and electronic transmission of articles. It was also expected that the serials collections of HE libraries in these two major cities would meet a significant proportion of needs and the existence of local union lists of serials made identification of assets simple, at least in theory. Of course, a more anodyne message of partnership and co-operation was expressed publicly (Friend, 1996). Perhaps unsurprisingly the partners found running a document supply service tougher than expected and some of the delivery statistics were less than satisfactory. Against the BL's ability to shift millions of requests, LAMDA manages some tens of thousands. It was clear that the issues were administrative rather than technical. (Blunden-Ellis, 1996). But LAMDA did and does provide thousands of cheap requests and helped to achieve perhaps its main goal of breaking the mould and opening up the market for a wealth of new technical possibilities.

The second project, and the one receiving the biggest budget share, was InfoBike, based at Bath University and which can be said to have failed in terms of its expressed and very ambitious goals. The fundamental system concept was to separate resource discovery, or searching bibliographic catalogues, from access to electronic document stores, and the delivery of material from these. This demanded complex development work. Interestingly, the project managed to develop and change as the work plan progressed. First it turned into the BIDS JournalsOnline service, which in turn provided the core of the spin-off company ingenta, which is now a very successful multi-million AIM-listed company.

The third project, SEREN was a project based in Wales aiming to provide a regional service through a distributed resource discovery model. It aimed to provide the software to enable the Welsh HE community to maximise use of the library resourcebase in Wales before turning to BLDSC and other suppliers. It proposed to use simple 
Internet mail protocols available even to small libraries, to allow the scanning of documents and their transmission as attachments to e-mail messages. The project was a useful learning component of the programme, but in practice and as so often it was the hurdle of co-operation which proved the most daunting.

The final project was EDDIS, based at the University of East Anglia, which aimed to produce an integrated, end-user driven identification, holdings discovery, ordering and electronic supply service for non-returnable items (typically journal articles) which could be used by all UK higher education institutions. Again this changed during the course of the project with the involvement of the commercial Fretwell Downing group. It was also the only one of the projects to work with BLDSC (Larbey, 1998).

By the end of the decade, eLib had at least assisted in achieving its mould-breaking role, even if the projects other than LAMDA had more or less withered. Technology had allowed a proliferation of rival services to emerge. The EDDIS study concluded that it was a range of non-technical issues such as copyright, culture, critical mass of titles and the like which really mattered (Larbey, 1998). Yet a study at the University of Liverpool compared six services and concluded that although the BL still provided a fast reliable service with the greatest breadth of journal coverage, its failure to deliver on sophisticated interfaces which the new technology offered was a source of concern, as more limited services were easier to use. Nevertheless for a multi-faculty HE institution it was still the best option - but now with BIDS and UnCover as serious rivals (Boyle and Davies, 1999).

\section{The National Site Licensing Initiative}

As JISC structures developed and expanded, the pressure increased to give access to the primary literature. The National Electronic Site Licensing Initiative (NESLI) evolved from the three year Pilot Site Licence Initiative (1995-1997) and the original NESLI (1998-2001), which introduced the concept of a managing agent and piloted the use of a model licence for use in negotiating agreements with publishers. A second phase called NESLi2 has now been put in place. Content Complete Ltd (CCL) provides outsourced negotiations and related support services to academic and research libraries and institutions for digital content. CCL's partner is MIMAS, the JISC/ESRC supported national data centre at Manchester, which provides the helpdesk and communications functions.

Publishers had no real idea how to respond to the challenges of new technology in terms of pricing except, it appeared, to keep pushing prices up. The barrier of VAT on electronic only publications hampered substantial innovation in the UK and it seemed that the best that could be done was to develop the consortial approach now the dominant model in the USA. Superficially these "big deals" seemed attractive, but some publishers simply refused to take part while some demanded longer term deals than were comfortable and a realisation began to dawn that perhaps this militated against the interests of smaller publishers. Some railed that the development of the STM model was inappropriately colouring the development of e-journals, since it dealt with the minority of very large publishers, rather than the huge majority of very small publishers. 
The midpoint evaluation of NESLI found widespread acceptance of the value of a national negotiation service. However, many stakeholders considered that progress had been slow, that the process was complex and offers did not always provide value for money. Indeed the tide seems now to have turned against big deals, it seems, but what will not now change is a user expectation of direct unmediated online access to the literature. Indeed the whole future of scholarly communication is a matter of substantial debate.

\section{The future of scholarly communication: a brief guide to the debate}

The growing debate on the future of scholarly communication has its origins in the journals financial crisis in libraries, but the discussion which has opened up has little to do with resolving that issue: it is purely an academic debate on the future of scholarly communication.

There are some 20-25,000 peer reviewed academic journals publishing about $2,500,000$ articles each year. As their prices continue to rise they become less available in libraries, while the restrictive practices of publishers somewhat curiously make access even more limited even to online journals.

Two related movements have grown together to form the so-called gold route and green route to changing the face of scholarly publishing. The one with the highest profile is the so called gold route of publishing in open access journals. Some 5 per cent of journals - about 1,000 - are published as purely online journals with the full panoply of peer review and accreditation. Most of these are listed in the Directory of Open Access Journals (DOAJ) (www.doaj.org/), a list of entirely free journals. In addition to these the biosciences have spearheaded a variant model in which in return for author charges the journal is made available free across the web. The two major activities here are the Public Library of Science (www.plos.org/) and Biomed Central (www.biomedcentral.com/), which publishes over 100 journals online. In the latter case the Funding Councils have paid a central subscription for the UK so that UK scientists can publish without charge. A whole raft of public bodies is beginning to line up to offer to pay authors charges on the grounds that the results of publicly funded research should be in the public domain. The Wellcome Trust (www.wellcome.ac.uk/en/1/awtprerel1003n303.html), The Max Planck Institute (www.biomedcentral.com/news/20031022/06), and in the USA the Howard Hughes

Institute (www.earlham.edu/ $\square$ peters/fos/ bethesda.htm) and a growing list of funding agencies have all said they will prefer the OAI model and will fund it. In 2004 the House of Commons Select Committee on Science and Technology (2004) reported on whether UK government funded research should be published openly. It concluded that the present model was no longer effective and made a case in favour of Open Access and institutional repositories, but, sadly, the DTI-led government response proposed that the Department of Terminal Inactivity should continue to live up to its name by simply denying that there was a problem.

Remember that this debate is about access and not the price of serials. Although the OAI "movement" to create journals free at the point of use is barely 18 months old, at least one journal already has an impact factor of four, while a growing body of evidence shows that articles published in OAI journals are cited at least three times 
more often than articles in commercial journals. So OAI brings greater exposure and citation. At present UK scientists submit a growing number of articles - 53 in January - to Biomed Central under the Funding Council Scheme, of which 47 per cent are accepted through peer review. So this is not a soft option.

However, many researchers worry about the RAE, the quality of OAI journals and the general novelty of it all. As a result the so-called "green route" has been developed. Computer scientists have developed standard interoperable software for e-print archives based mainly in universities. At the same time library organisations have negotiated copyright waivers with most publishers, so that articles from over 60 per cent (again a growing list) of publishers can be held locally

(www.sherpa.ac.uk/romeo.php). All that is required is for a copy of the article accepted by a publisher to be submitted in any standard format to a central institutional body, usually the library, which then deals with copyright and metadata tagging. Again the evidence is that this leads to a vast increase in access and citation, provided that this is consolidated in a central repository using the agreed standards and not strewn across personal web pages in a variety of ways. By extension if all academics follow this route, web harvesters will search and find material with ease. The major proponent of this is Steven Harnad at Southampton who argues the case online at http://lists.openlib.org/pipermail/ oai-eprints/2003-November/000108.html and in print (

\section{Conclusion}

Almost inevitably the pendulum has swung and relationships between the BL and HE have improved in the last few years, following a notable and welcome effort by the BL to repair the rift. (Anderson Report, 1996) followed on from the Follett Report and in turn led to the British Library/HE Taskforce (1999-2001). The Anderson report (never definitively published) focused on a national and regional strategy for library provision for researchers. The Research Support Libraries Programme (RSLP), was then funded by the four higher education funding bodies, to implement key proposals from the Anderson Report.

The Research Support Libraries Programme (RSLP) was designed specifically to support and improve library provision for research in higher education, with a strong focus on promoting collaboration ranging from easier access to collections to the creation of digital libraries. The programme ended in the summer of 2002 having distributed grants of almost $£ 30$ million to universities over four years. It is also worth noting that the BL was a partner in 17 of the RSLP Projects compared with almost none of FIGIT's 60 -odd projects.

The joint British Library/HE Taskforce was set up to identify areas for future collaboration between the British Library and higher education and implicitly to build bridges and revive relationships. The Task Force sought specific initiatives for common benefit, in line with the British Library's increasing strategic emphasis on collaboration as a mechanism to deliver its own objectives. One consequence of this coming together is the creation of the Research Libraries Network, hosted by the British Library but aiming to link the national libraries and HE research libraries. It remains a matter of debate whether this is the wrong answer to the right question, but at least it demonstrates that the season of goodwill persists. Certainly, both groups are 
more than ever at the mercy of external forces and it does seem that commercial document supply will slowly wither on the vine as unmediated desktop access to the internet becomes the norm. The key for both parties will be how far they can create value-added services that will be perceived as relevant to the end-user.

There is one last irony in this trot through 25 years of BL and HE relations. In 1980 the BL ceased to publish the British Union Catalogue of Periodicals, a costly publication deemed largely superfluous given the comprehensiveness and quality of BLDSC collections and services. The last act of the JISC before RLN takes shape under the wings of the BL, is to launch SUNCAT, a Serials UNion CATalogue for the UK. Its aim is to improve access for researchers rather than to stimulate document supply and one of its principal components is to list the serials holdings of the BL, without which no serious research could begin. One would love to hear the Line line on this, although his views on the value of co-operation may still hold true (Line, 1997).

\section{References}

Anderson Report (1996), Joint Funding Councils' Libraries Review, report of the Group on a national/regional strategy for library provision for researchers, available at: www.ukoln.ac.uk/ services/elib/ papers/other/anderson, .

Baker, D. (1992), "Access versus holdings policy with special reference to the University of East Anglia", Interlending \& Document Supply, Vol. 20 No.4, .

Blunden-Ellis, J. (1996), "LAMDA - a project investigating new opportunities in document delivery", Program, Vol. 30 No.4, .

Boyle, F., Davies, M. (1999), "Access versus holdings: document delivery realities", The Electronic Library, Vol. 17 No.2, .

Brindley, L. (1996), "FIGIT - RIP?", JISC News, No.1, .

E-SYS (2000), "Summative evaluation of phases 1 and 2 of the e-lib initiative: final report", available at: www.ukoln.ac.uk/ services/elib/ info-projects/ phase-1-and-2evaluation/ elib-fr-v1-2.pdf, .

Friend, F. (1996), "LAMDA: questions and some answers", Interlending \& Document Supply, Vol. 24 No.3, .

Harnad, S. (2004), "Open access to peer reviewed research through author/institution self-archiving", in Andrews, J. (Eds),Digital Libraries: Policy Planning and Practice, Ashgate Press, Aldershot, . 
Higher Education Funding Council for England (1993), Joint Funding Council's Libraries Review Group: Report (The Follett Report), HEFCE, Bristol, .

House of Commons Select Committee on Science and Technology (2004), 10th Report, Scientific Publications: Free for All?, House of Commons, London, .

Larbey, D. (1998), "Project EDDIS", Ariadne, No.14, .

Law, D. (1995), "The development of a national policy for dataset provision in the UK: a historical perspective", Journal of Information Networking, No.1, .

Law, D. (1999), "The British Library and the impact of research", Information Services and Use, Vol. 19 No.2,

Line, M. (1995), "Opinion paper: access as substitute for holdings: false ideal or costly reality?", Interlending \& Document Supply, Vol. 23 No.2, .

Line, M. (1997), "Co-operation: the triumph of hope over experience?", Interlending and Document Supply, Vol. 25 No.2, .

Parent, I. (2004), "The IFLA UAP and UBC Programmes", Alexandria, Vol. 16 No.2,

Pocklington, K., Finch, H. (1987), Research Collections under Constraint, British Library, London, British Library Research Paper, .

Rusbridge, C. (2001), "After eLib", Ariadne, No.26, .

Tuck, B. (1995), "Electronic document delivery: technical aspects and future developments", in Collier, M. (Eds),Electronic Library and Visual Information Research (ELVIRA 1), ASLIB, London, .

University Grants Committee (1976), Capital Provision for University Libraries: Report of a Working Party [The Atkinson Report], HMSO, London, .

\section{Further Reading}

Association of Research Libraries (2005), for the inquiring mind dedicated FAQ pages and a bibliography of URL's can be found at:

www.arl.org/scomm/open_access/framing.html, .

Eason, K. (2001), "Evaluation of the National Electronic Site Licence Initiative (NESLI)", Serials, Vol. 14 No.2, . 
Larbey, D. (1997), "Project EDDIS", Interlending \& Document Supply, Vol. 25 No.3,

[Manual request] [ Infotrieve]

\section{About the Author}

\section{Derek Law}

is Head of the Information Resources Directorate, University of Strathclyde, Glasgow, UK. 